\title{
A LEITURA DE TEXTOS LITERÁRIOS NAS AULAS DE LÍNGUA INGLESA: DESENCONTROS ENTRE TEORIA E PRÁTICA
}

\author{
The Reading of Literary Texts in English Classes: Dislocations between Theory \\ and Practice
}

\author{
Dayse Paulino de ATAIDE, UFPR ${ }^{1}$
}

RESUMO: O presente trabalho visa refletir acerca do papel da leitura de textos literários nas aulas de inglês no Ensino Médio da rede estadual do Paraná. Para tanto, um levantamento bibliográfico de algumas teorias que abordam a literatura como uma importante aliada na formação do indivíduo e no ensino da língua inglesa é realizado a fim de perceber possíveis causas da defasagem nos índices de leitura literária em relação ao idioma estrangeiro. Após as considerações teóricas, respostas a um questionário destinado aos professores de inglês do Ensino Médio da rede estadual do Paraná são analisadas, no intuito de levantar possíveis fatores que acarretam na desarticulação entre teoria e prática, língua e literatura.

PALAVRAS-CHAVE: Literatura; Ensino; Língua Inglesa; Leitura literária.

ABSTRACT: This work aims to analyze the role of reading literary texts in high school English classes in public schools of Paraná. A bibliographical review of theories which approach Literature as an important ally in individual development as well as in English teaching is done in order to perceive the obstacles which justify the discrepancy in the index of literary reading in relation to a foreign language. Answers to a questionnaire designed for high school English teachers in public schools of Paraná are also accessed and interpreted. The purpose of the present work is to throw light on some factors that lead to dislocation between theory and practice, language and Literature.

KEYWORDS: Literature; Teaching; English language; Literary Reading.

\section{INTRODUÇÃO}

Já assegurava Candido (1995) que a literatura é um poderoso instrumento que transforma o homem em vários sentidos. Ela o desperta para os diversos aspectos da vida (histórico, social, cultural, econômico, e emocional) e para os conflitos que o rodeiam, pois "ela não corrompe nem edifica, portanto; mas, trazendo livremente em si o que chamamos o bem e o que chamamos o mal, humaniza em sentido profundo, porque faz viver" (CANDIDO, 1995, p. 244).

\footnotetext{
${ }^{1}$ Mestranda em Estudos Linguísticos (UFPR).dya12ataide@gmail.com.
} 
Essa ideia não está distante do que propõem as diversas abordagens metodológicas que envolvem o processo de ensino-aprendizagem de línguas estrangeiras modernas, em especial no que se refere às habilidades de leitura literária, foco desse trabalho. Nesse sentido, é possível afirmar que estudiosos, pesquisadores, professores e outros profissionais dessa área vêm investindo tempo e trabalho na busca por novas alternativas que objetivem tornar o processo mencionado (Ensino de lem com foco na leitura de literatura) mais eficiente.

Tendo em vista a questão levantada, esse artigo trata do papel do trabalho com a literatura nas aulas de inglês do Ensino Médio (doravante EM) de instituições públicas, estaduais ou federais, de Curitiba. O interesse por essa área decorre da percepção de que existem dificuldades em inserir a literatura no cotidiano do ensino de língua inglesa de maneira efetiva. Vale esclarecer que apesar dos problemas discutidos no decorrer da pesquisa também serem pertinentes ao ensino de língua portuguesa e literatura brasileira, alguns fatores justificam a relevância de se trabalhar com as dificuldades de leitura em língua estrangeira, mesmo que existam barreiras ainda não transpostas na leitura em língua materna.

Quando o assunto é leitura de literatura, não parece haver diferença significativa, em termos de processos cognitivos, entre os textos escritos em língua materna ou estrangeira. De acordo com Candido (1995), independentemente das questões linguísticas, a literatura pode propiciar aos estudantes um diálogo que lhes auxilia a entender seus próprios conflitos e aqueles dos indivíduos que os cercam. Parafraseando o autor, a leitura literária desperta os indivíduos para uma nova vida, modificando-os a cada experiência na qual eles interagem com a obra literária.

É certo que o assunto literatura em sala de aula está recebendo cada vez mais atenção. Contudo, constata-se através de pesquisas, de falas de alunos e mesmo de professores, que é delegado à ela um papel de menor importância, tanto nas aulas de língua portuguesa quanto nas de língua inglesa, disciplinas obrigatórias em boa parte das escolas brasileiras. Desse modo, o problema da leitura literária é análogo nos dois idiomas, conforme pode ser constatado nos comentários da pesquisa sobre questões envolvendo a leitura em geral, inclusive a literatura, realizada por Aguiar (2013).

A língua inglesa é uma disciplina obrigatória inserida na grade curricular do EM há bastante tempo em muitas escolas brasileiras, como pode ser verificado na pesquisa encaminhada por Gimenez, Perin e Souza (2003). Apesar desse tempo, a leitura literária não conquista um espaço significativo nas aulas de inglês, algo que prejudica o 
desenvolvimento de outras habilidades, como as de interpretação, inferências e conhecimento de mundo. As hipóteses levantadas para a explicação desse fenômeno estão conectadas ao fato de que não é comum que os estudantes brasileiros tornem-se leitores, o que ocorre por várias razões. Uma delas é que o ensino de inglês nas escolas públicas, de uma forma geral, persiste em abordar o texto visando atender objetivos gramaticais e lexicais. Há pouco espaço para introduzir o hábito de leitura e o prazer que a literatura pode proporcionar aos indivíduos. Isso pode resultar do fato de que muitos professores de inglês não são proficientes na língua e/ou desconhecem como explorar obras literárias em sala de aula, mesmo que eles mesmos leiam frequentemente.

Dessa forma, nesse trabalho, a partir do estudo de teorias e documentos que norteiam o ensino de línguas estrangeiras modernas, é colocado em evidência o papel da leitura de textos literários em inglês no ensino médio e as barreiras que impedem ou interferem no encontro de duas vertentes tão importantes para o indivíduo em processo de formação. Isso se explica porque, apesar de existirem muitos estudos que recomendam a inserção efetiva da literatura no EM, não tem havido um avanço significativo no número de leitores de textos literários no Brasil, conforme aponta Aguiar (2013). Assim, é bastante relevante refletir sobre aspectos que afetam o desenvolvimento dessa habilidade que engloba a vida do ser humano em vários sentidos, tal como mencionado por Candido (1995).

\section{LEITURA E LITERATURA}

Parece haver consenso entre pesquisadores (LAJOLO, 1982; MARTINS, 2006; AGUIAR, 2013; BORDINI e AGUIAR, 1993) que a leitura, em geral, é um importante instrumento de ensino, devendo ser incentivada desde as séries iniciais da educação básica. No entanto, apesar do valor que é atribuído a essa atividade, ainda há a impressão, a partir de Lajolo (1982), que poucos professores têm clareza sobre o que é leitura e qual é o seu papel na educação. Em diversas ocasiões, o texto é utilizado apenas como pretexto para ensinar conteúdos de natureza gramatical. De acordo com Aguiar,

[...]ler é a atividade de decodificação de um texto, de percepção e interpretação dos sinais que se apresentam de forma ordenada, guardando entre si associações de sentido. Ler, no entanto, não é apenas decifrar um código: é perceber a interligação lógica dos significados, as relações entre eles e, o que é mais importante, assimilar o pensamento e as intenções do autor, confrontar as 
ideias apreendidas com os conhecimentos anteriores sobre o assunto, dialogar com o autor, posicionando-se diante dele, e utilizar os conteúdos ideativos adquiridos em novas situações (2013, p. 153).

Assim, ler significa interagir e participar de um outro mundo que ao mesmo tempo pertence ao leitor também, uma vez que esse ser, pertencente a uma comunidade que não está distante do que o texto traz e propõe, se apropria de um universo até então desconhecido ou pouco explorado. Conforme Aguiar (2013), essa concepção de leitura visa transformar a relação do leitor tanto com o conteúdo lido quanto com o escritor que o produz. Dessa forma, o indivíduo adquire a capacidade de dialogar com aquilo que recepciona, sem aceitar passivamente as informações que lê como verdades absolutas. Pelo contrário, ele reconstrói o produto lido de acordo com as próprias crenças e experiências.

A professora afirma também que é muito importante que os alunos tenham acesso a textos de vários gêneros, a fim de se apoderar dos diversos discursos que circulam na sociedade. Além disso, o leitor tem a oportunidade de aumentar seu conhecimento de mundo acerca dos mais variados assuntos, seu repertório cultural e acumular experiências no decorrer de suas leituras (AGUIAR, 2013). Contudo, Aguiar (2013, p.159) afirma que é "na área da ficção que o prazer da provocação aumenta", é no contato literário que o leitor é mais desafiado a descobrir "modos alternativos de ser e de viver" (p.160). Em consonância com os escritos da professora brasileira, o texto Standards for the English Language Arts, declara que:

A aprendizagem de língua depende da exploração e de um cuidadoso estudo de uma vasta variedade de textos. Em particular, os estudantes precisam ler literatura, incluindo os textos clássicos, contemporâneos, e narrativas populares, poemas, canções e peças teatrais. A exploração de mundos literários concede aos estudantes uma nova perspectiva de sua própria experiência e os capacita para descobrir como a literatura pode capturar a riqueza e complexidade da vida humana. (NCTE, 1996, p. 11$)^{23}$ (tradução nossa)

\footnotetext{
${ }^{2}$ No original: "Language learning depends on the exploration and careful study of a wide array of texts. In particular, students need to read literature, including classic, contemporary, and popular narratives, poems, songs, and plays. Exploring literary worlds gives students a new perspective on their own experience and enables them to discover how literature can capture the richness and complexity of human life." (NCTE, 1996, p. 11)

${ }^{3}$ A presente citação foi retirada do National Council of Teachers of English, uma associação americana composta por educadores cujo intuito é auxiliar professores que atuam no ensino de língua inglesa e artes, citando os conteúdos curriculares que devem ser inseridos ao longo da formação na educação básica. A citação do documento americano foi utilizado apenas para indicar que o texto literário pode ser usado no contexto brasileiro, mas não significa que o NCTE deve ser norteador no Brasil.
} 
$\mathrm{O}$ excerto acima aponta para alguns fatores relevantes para esse trabalho. Um deles diz respeito à literatura como um elemento essencial a ser explorado no processo de ensino-aprendizagem de línguas. Até nas aulas de um segundo idioma, a potencialidade da literatura é alta quando ela é introduzida no cotidiano dos estudantes, apesar das dificuldades que afetam seu ensino. A literatura, cujo papel não se restringe em propiciar prazer às pessoas, também pode conduzi-las às peculiaridades linguísticas, pois essas duas áreas estão articuladas, não justificando a compartimentalização existente entre elas. É importante estabelecer que os seres humanos interagem e se afirmam no mundo por intermédio da língua, enquanto a literatura influencia o modo dos homens conceberem o mundo.

\subsection{A literatura como um direito fundamental e o papel da escola}

De acordo com Candido (1995), a literatura deve ocupar um espaço ao lado de itens básicos que asseguram qualidade de vida a todos os habitantes. Candido justifica esse posicionamento no momento em que afirma que é extremamente necessário também ensinar o estudante a agir reflexivamente e não aceitar as informações recebidas de uma forma passiva, sem questionar a sua validade.

No decorrer do seu texto $O$ direito à literatura, o referido autor aborda as diferenças socioeconômicas e culturais existentes entre as classes, citando a década de 1980 como o período em que os segmentos menos abastados da sociedade começaram a ser observados sob um prisma diferenciado, se comparado às décadas anteriores. Disso decorre que as "injustiças sociais" - em termos de acesso à cultura, alimentação de qualidade e moradia adequada, por exemplo - cometidas contra as classes mais populares começaram a incomodar e constranger a população, influenciando as obras literárias posteriores.

Apesar do que foi citado, Candido não deixa de apontar a hipocrisia da sociedade, pois apesar de "reconhecer que aquilo que consideramos indispensável para nós é também indispensável para o próximo" (CANDIDO, 1995, p. 239), o autor questiona se o que a classe dominante reivindica para as outras é válido quando o assunto é cultura, não somente destinada aos indivíduos com maior poder aquisitivo e com fácil acesso à leitura. No contexto de ensino-aprendizagem em língua inglesa, é também realidade das escolas brasileiras que a oferta de literatura estrangeira não ocupa um espaço significativo nas 
salas de aula. Até certo ponto, isso pode estar atrelado à ideia de que os estudantes de línguas não são capazes de ler e/ou entender a complexidade de um texto literário escrito no idioma estudado. Insistindo nos direitos humanos, Candido foi assertivo ao se referir à literatura como bem incompressível ${ }^{4}$, assim como alimentação, moradia, vestimenta, educação e saúde. Segundo ele,

a luta pelos direitos humanos pressupõe a consideração de tais problemas, e chegando mais perto do tema eu lembraria que são bens incompressíveis não apenas os que asseguram sobrevivência física em níveis decentes, mas os que garantem a integridade espiritual. [...] Elas [arte e literatura] só poderão ser consideradas bens incompressíveis segundo uma organização justa da sociedade se corresponderem a necessidades profundas do ser humano, [...].”(CANDIDO, 1995, p. 241).

No fragmento acima torna-se evidente que o crítico estimula seus leitores a refletirem acerca dos motivos da incompressibilidade da literatura. A resposta dada por ele é relativamente simples: ela representa o que a sociedade reivindica para si e ajuda a formar o que ela é, por intermédio de contos, fábulas, crônicas, entre outros diversos gêneros, que visam atender a todas as esferas sociais. Sobre essa questão, Candido também menciona que a obra literária não está desvinculada do social, pois o autor não produz no vazio, uma vez que ele está inserido em uma realidade que não o manterá distante de seus valores e crenças, ou seja, "a literatura aparece claramente como manifestação universal de todos os homens em todos os tempos" (1995, p. 242).

É certo que Candido escreve sobre literatura sem enfocar em língua materna ou estrangeira. Contudo, o que o teórico diz se aplica ao tema desta pesquisa, pois o que se afirma na teoria é pouco visto na prática. Muitos professores afirmam que exploram o texto literário em língua inglesa nas aulas, mas a maneira como isso é feito geralmente não contempla as potencialidades da literatura, conforme será retomado mais adiante.

Em um texto anterior ao mencionado, Candido (1972) evidencia que a literatura possui muitos papéis. Além de propiciar prazer estético às pessoas, existem outros propósitos, como a coesão e coerência apresentadas pelo teórico. Também não cabe à ela ensinar ao leitor como identificar uma escola literária ou sua forma e estrutura. De acordo

\footnotetext{
${ }^{4}$ Consideram-se bens incompressíveis aqueles que não podem ser negados aos indivíduos, conforme estabelecido na Constituição Federal. De acordo com o documento, todos os indivíduos têm direito à cultura, alimentação, moradia, segurança, liberdade de expressão e crenças, entre outros. Para Candido, a literatura é também um direito de todos os indivíduos e assim sendo, não pode ser comprimido.
} 
com o autor, não se deve abandonar os aspectos formais da obra, mas a literatura tem outras funções, que não se restringem a isto, a saber:

[1] Função psicológica: Candido afirma que há uma "necessidade universal" por ficção e fantasia. A obra ficcional traz a fantasia, mas de alguma forma sua linguagem está conectada ao modo de viver do homem, por isso "a fantasia quase nunca é pura" (1972, p. 805). O teórico explica que é impossível criar uma obra sem que haja qualquer referência ao mundo real. $\mathrm{O}$ que faz o ser humano se identificar com o produto lido é que ele busca consolo para os conflitos ou algum ponto de apoio naquilo que lê e que verdadeiramente enfrenta no seu cotidiano.

[2] Função Formativa (personalidade): Forma no sentido contrário do que a pedagogia tradicional propõe para o processo de ensino-aprendizagem de literatura. Em aulas mais convencionais, o que costuma aparecer é a utilização do texto literário como uma maneira de ensinar valores aos indivíduos, comportamentos humanos e história geral. Candido (1972) acredita que o texto literário não tem como papel impor padrões de moral e conduta ao leitor, mas deve conduzi-lo à constante reflexão, que vai além do que o leitor espera e vivencia. Por também ser conhecida como função da personalidade, influencia o modo como os indivíduos lidam com a realidade e com a própria vida.

[3] Função do conhecimento de mundo e do ser: Como dito anteriormente, a literatura transporta o indivíduo para os conflitos dele e da sociedade, em geral. Parece claro que os textos literários oferecem ao leitor informações históricas, sociais, culturais, econômicas, entre outras que afetam a maneira como o sujeito concebe o mundo. Além disso, tanto o autor quanto o leitor do texto são indivíduos que estão inseridos em um dado contexto, que vai servir de base para a produção da obra literária e, consequentemente, para a apreciação e interpretação por parte do leitor.

Relacionando essas funções às aulas de inglês, quando o professor se propõe a introduzir o texto literário, ele tem o dever de fazer com que seus alunos interajam com esse texto, mesmo quando se trata de uma língua diferente a da deles. É claro que as implicações linguísticas não perdem espaço diante dessa concepção de ensino de literatura, mas elas não são as protagonistas da história. Nesse sentido, Cruz (2010, p. 1) defende que a

língua é um receptáculo e um transmissor de hábitos, tradições, rotinas, em um contexto social e econômico, entre outras muitas coisas e, quando dominada via literatura ou poesia, pode refletir a alma humana. [...] A literatura realça o Ensino de Língua Inglesa 
através de elementos tais como material autêntico, língua em uso e representação estética da língua falada, bem como o enriquecimento da língua e cultura. É com esse último elemento que a literatura abre a porta que conduz a uma visão mais ampla e mais próxima da cultura (ou culturas) onde a língua alvo é falada. (tradução nossa). ${ }^{5}$

Nesse panorama de ensino-aprendizagem da língua mais falada do mundo, a escola é a instituição em que a literatura pode atuar e cumprir o seu papel humanizador. Conforme Candido (1995), humanização significa um olhar apurado sobre si e sobre o mundo, de forma crítica, reflexiva e sensível, capaz de perceber a complexidade do ser humano enquanto sujeito transformador da realidade que o cerca e o afeta, simultaneamente.

Relacionando o que Candido explorou no decorrer dos seus textos ao atual momento da literatura no ambiente escolar, e a partir de estudos realizados pela professora Martins (2006), nos quais a professora destaca as pesquisas de Beach e Marshall, não há dificuldades em encontrar teorias que tratem da inserção dessa matéria no currículo do EM. Contudo, segundo ela, uma parcela significativa dos professores de língua não tem o conhecimento de como fazer isso, pois desconhecem a existência de uma base teóricometodológica sólida que os auxilie na formação de alunos-leitores. Isso acaba, muitas vezes, conduzindo os profissionais a escolhas errôneas e pouco satisfatórias.

A professora salienta que, embora textos literários estejam presentes no cotidiano da escola, eles são usualmente submetidos ao estudo de regras gramaticais ou reduzidos a perguntas sobre a estrutura da obra e questões similares. Na ótica de Martins (2006), o encaminhamento inadequado do trabalho com o texto literário ao longo da formação do estudante afeta negativamente a relação entre obra e leitor e as aulas se tornam difíceis e pouco proveitosas. Na avaliação dela, ao contrário da realidade de hoje, "ao longo da trajetória escolar, da educação infantil ao ensino médio, a leitura literária deveria ser mais valorizada como meio de o aluno desenvolver a criatividade e a imaginação na interação com textos que inauguram mundos possíveis, construídos com base na realidade empírica" (MARTINS, 2006, p. 84).

\footnotetext{
${ }^{5}$ No original: "[...] language is a receptacle and a transmitter of habits, traditions, routines, social and economical context, among many other things and, when mastered via literature or poetry, it can reflect the human soul. [...] Literature enhances ELT through elements such as authentic material, language in use and aesthetic representation of the spoken language, as well as language and cultural enrichment. It is with this last element that literature opens the door that leads to a wider and closer look on the culture (or cultures) where the target language is spoken." (CRUZ, 2010, p. 1).
} 
A pesquisadora ainda menciona outros problemas que prejudicam o ensino dessa área. Um deles é que pouca voz é atribuída aos estudantes; são raros os momentos em que os saberes prévios deles e a experiência dos alunos enquanto leitores são valorizados e colocados em discussão, limitando a capacidade crítica desse público. Assim, as aulas são norteadas apenas pelos conteúdos que o livro didático traz, o que as torna monótonas e desinteressantes.

Em casos mais recorrentes, os alunos não sentem vontade de interagir com a leitura literária e o que eles vivenciam no cotidiano, fora do ambiente escolar, não é confrontado com o que eles leem em sala, sob orientação do professor. Nesse sentido, uma aula de literatura acaba se restringindo às respostas prontas dos manuais didáticos que se manifestam na voz do professor que, por sua vez, impõe ao educando sua própria leitura, baseada na sua própria experiência leitora e conhecimento de mundo.

Dessa forma, Martins declara, a partir da leitura dela de outros autores, que "o professor deveria confrontar o aluno com a diversidade de leituras do texto literário, para que o educando reconheça que o sentido não está no texto, mas é construído pelos leitores na interação com textos” (2006, p. 84). Ela acrescenta que dificilmente esse cenário mudará enquanto a escola insistir em tratar o livro apenas como um objeto estético a ser apreciado. A leitura literária vai além da sua esteticidade; a finalidade da leitura de textos literários é a possibilidade constante de discussão e a reflexão a partir do que é abordado na obra. Assim, a literatura também não pode nem deve ser concebida de maneira desarticulada, como mais uma vertente no ensino de língua, pois nela residem muitas práticas que não se restringem aos aspectos estruturais ou linguísticos, conforme apontado por Candido (1972). A escolha dos textos deve acompanhar as demandas sociais, históricas, culturais e econômicas de dado contexto.

Contudo, assim como ocorre em outras disciplinas do currículo, dificilmente se encontram no processo de ensino-aprendizagem da língua inglesa políticas que facilitem a atividade proposta pelas teorias discutidas ao longo do trabalho. Por exemplo, encontrar obras literárias completas nas prateleiras da biblioteca da escola, até mesmo as adaptadas, revela-se uma tarefa difícil. Nessa linha, também é muito comum que os livros didáticos tragam apenas excertos de romances, contos e crônicas que, muitas vezes, são as únicas experiências de leitura literária dos alunos, quando eles se dispoem a ler. Isso se justifica porque o livro, um aparato que deveria funcionar como um apoio na condução das aulas, se constitui, muitas vezes, no único material didático disponível para professores e 
estudantes de maneira facilitada e gratuita. Sobre essa fragmentação dos textos literários nas obras didáticas e sua relação com o estudante, afirma-se que:

[...]O leitor se expõe ao ler, se desapropria de si mesmo para se confrontar com a alteridade e descobrir, in fine, a alteridade que está nele.

Entretanto, para que ocorram esses fenômenos, é preciso que os alunos tenham acesso às obras integrais. É ilusório esperar viver essa experiência na escola a partir unicamente da leitura de um fragmento. É por isso que a atividade de leitura em sala de aula é frustrante quando feita a partir de trechos selecionados. Ao lado do tempo de estudo, a leitura integral efetuada na esfera privada é a única capaz de modificar a relação dos alunos de ensino médio com o texto. (ROUXEL, 2013, p. 28).

Com base nesses apontamentos, estabelecer uma relação que ultrapasse os muros da escola torna-se uma incumbência cada vez mais complicada. Dificilmente o aluno adquire o hábito de leitura literária se essa atividade não é desenvolvida apropriadamente no espaço adequado para isso. Considerado que a leitura de literatura é processual, os professores enfrentarão um desafio maior na formação de leitores enquanto continuarem com a leitura fragmentada dos textos. Contudo, esse tipo de estratégia parece ser o único caminho para os professores que enfrentam uma longa jornada de trabalho em sala de aula, confrontam-se com condições inadequadas na instituição onde lecionam (pela falta de material pedagógico, por exemplo) e/ou se sentem despreparados para a prática docente.

A escola é o espaço onde o cidadão deve aprender a se relacionar com a literatura. Sobre essa questão, Zilberman (2009) afirma que a leitura literária ainda não tem um papel de destaque nas escolas brasileiras, especialmente no contexto das classes populares, oferecendo um grande desafio aos educadores. A professora acrescenta que a literatura ainda pode favorecer a leitura de outros gêneros discursivos, demonstrando assim a preocupação em preparar o leitor para interagir com a língua em diversas esferas sociais. Também é dever do professor promover a articulação entre os aspectos referentes à estrutura e ao conteúdo da obra literária. Isso confirma a riqueza que o texto literário apresenta na vida do estudante, convidado a experimentar um "sentimento de prazer motivado não apenas pelo arranjo convincente do mundo fictício proposto pelo escritor, mas também pelo estímulo dado ao imaginário do leitor, que assim navega em outras águas, diversas das familiares a que está habituado" (ZILBERMAN, 2009, p. 18). Assim, 
ao mesmo tempo em que a fantasia alimenta a alma e a mente do indivíduo, ela as mantém alertas para os fatos cotidianos presentes na sociedade.

\section{ANÁLISE DOS RESULTADOS DO QUESTIONÁRIO}

Em qualquer trabalho que envolve a prática docente, é muito importante ouvir o que os professores têm a dizer a respeito do assunto tratado. No caso da presente pesquisa, os resultados aqui apresentados foram obtidos a partir de um questionário via Internet (ele foi disponibilizado, respondido e analisado no decorrer do $1^{\circ}$ semestre de $2015^{6}$ ), composto por 12 questões, sendo 7 objetivas e 5 subjetivas. Essa alternativa foi escolhida por abranger melhor o universo de pesquisa - professores de inglês do EM da escola pública, estadual ou federal, de Curitiba - em menor tempo.

O total de respondentes do questionário, cujo link foi disponibilizado através de e-mails e mensagens em redes sociais, foi de 25 pessoas. Esse número está dentro do esperado, considerando que a média de retorno do método utilizado nesta pesquisa alcance 25\% (MARCONI e LAKATOS, 2002, p. 98). No total, o link da pesquisa foi enviado para, aproximadamente, 100 e-mails fornecidos pelas instituições de Curitiba, disponíveis na página eletrônica da Secretaria de Educação do Estado do Paraná.

A análise dos dados obtidos pelo questionário indicou que a maioria dos professores se declaram leitores de textos literários e consideram que o trabalho com a literatura nas aulas de inglês é muito relevante. Isso significa que esse público reconhece a importância da literatura na vida do ser humano, mesmo que nem todos os educadores a vejam como algo que interfira diretamente no desenvolvimento profissional deles. Um dos respondentes afirmou que "quando os alunos percebem que seu professor está lendo algo prazeroso eles também se interessam pela leitura e a buscam com maior frequência." $\left(\right.$ HUW MORGAN) ${ }^{7}$

Nas questões seguintes, os professores deveriam explicar se acreditam que a leitura literária contribui para a atuação profissional. De acordo com os resultados, é perceptível que os professores consideram a literatura um elemento muito importante na formação dos indivíduos e uma atividade bastante prazerosa. Mesmo assim, alguns não

\footnotetext{
6

do https://docs.google.com/forms/d/1vrVD54pE1HyfYtI4G4lElT1UeB15wMqJ8xy8iWMP5kM/viewform.

${ }^{7}$ Por desconhecer e/ou para preservar a identidade dos professores que responderam o questionário, as citações utilizadas como ilustração serão referenciadas pelos nomes dos personagens da obra How Green Was My Valley, de Richard Llewellyn.
} 
deixam de mencionar que, apesar de leitores, não intencionam inserir os textos em suas aulas, conforme será discutido mais adiante.

Entre as respostas mais recorrentes, os educadores citaram que os textos literários expandem as possibilidades de trabalhar com os temas presentes neles e ajudam no planejamento das aulas. Embora esse dado sugira que há entre os respondentes um entendimento de que a literatura aborda vários segmentos da sociedade, o texto literário não deve servir como pretexto para a seleção de material, sem que ele seja apreciado esteticamente pelos estudantes, que precisam descobrir, por eles mesmos, o que a literatura pode proporcionar.

É válido que os professores identifiquem na literatura as múltiplas possibilidades que os textos oferecem, como abordar certos assuntos ou entender os conflitos que envolvem os alunos, conforme mencionado nas respostas. Contudo, não é suficiente que apenas os educadores tenham acesso à leitura literária, afinal, os alunos também precisam ser expostos a ela e ter a possibilidade de participar ativamente de um mundo apresentado pela fala de seu professor. Além disso,

[...] se nós, professores, temos nossa própria nota sobre o livro, essa nota só é útil como uma hipótese para testar na interação da sala de aula e no exame minucioso contra passagens específicas, não como alguma coisa a ser registrada no caderno dos estudantes sem passar pela própria sensibilidade crítica deles"8 (BICKMAN, 1985 apud SHOWALTER, 2007, p.30) (tradução nossa).

Outro fator recorrente nas respostas do questionário diz respeito à motivação. Alguns professores afirmaram que o texto literário geralmente interessa os alunos, que, a partir do que é apresentado em sala, se sentem motivados a adquirir o hábito de leitura. Diante desse panorama, o professor deve ser sensível ao que os educandos necessitam. Isso não exclui a responsabilidade do educador na escolha dos conteúdos a serem trabalhados, porque se espera que a leitura dele seja mais experiente ao captar informações que possam não ter sido percebidas pelos estudantes. Por isso, é o professor que tem como papel intervir e adequar sua disciplina ao que os alunos precisam aprender.

Também era solicitado na questão 2 se os respondentes consideravam que a literatura contribuía para o seu desenvolvimento pessoal. Destacou-se nas respostas dos

\footnotetext{
${ }^{8}$ No original: "if we teachers have our own line on the book, that line is useful only as a hypothesis to test in the interplay of a class and in scrutiny against specific passages, not as something to be inscribed directly in student notebooks without passing through their own critical sensibilities." (BICKMAN, apud SHOWALTER, 2007, p. 30).
} 
professores que a literatura permite a ampliação de conhecimento de mundo. É interessante perceber que a resposta dos educadores concorda com a ideia defendida por Bordini e Aguiar (1993). As autoras afirmam que o texto literário encurta a distância existente entre o leitor e o conhecimento que ele adquire ao se relacionar com uma obra literária.

Além disso, os educadores citaram que a literatura amplia tanto o vocabulário quanto os horizontes dos alunos. Os dois fatores não representam uma novidade porque a partir do texto, a aquisição de vocabulário é natural, não é um aspecto a ser analisado isoladamente, assim como não é apenas o significado literal da palavra ou expressão que importa, mas o sentido que é atribuído a ela no decorrer do texto. As escolhas lexicais pelas quais o autor opta não são gratuitas; elas fazem parte de um contexto no qual a obra está inserida. No que se refere à ampliação de horizontes, os respondentes demonstraram a crença que eles mesmos podem ir mais longe quando entram em contato com o texto literário, o que, consequentemente, poderia melhorar a qualidade das aulas.

Além do que já foi dito, nas respostas dadas à terceira questão surgiu ainda a ideia que a literatura permite que os indivíduos: [a] interajam com o ambiente em que estão inseridos e com outros indivíduos, o que facilita o aumento da sensibilidade, a superação de problemas pessoais e a transformação deles, conforme citado pelos professores; [b] examinem a si próprios, se conheçam com mais profundidade; [c] ampliem os conhecimentos culturais de outros países, especialmente onde o inglês é o idioma oficial; [d] desenvolvam o intelecto, tanto pessoal quanto emocionalmente. Em relação à interferência na disciplina de língua inglesa, uma média de 10\% dos respondentes ressaltaram que o trabalho com o texto literário auxilia no levantamento de tópicos para posterior discussão, bem como possibilita o diálogo com outras disciplinas.

Avaliando todo o questionário, a questão 4 é uma das que mais chamam a atenção. É certo que essa pergunta obteve apenas três respondentes ${ }^{9}$. Apesar do baixo número, as respostas são condizentes com a terceira edição da pesquisa Retratos da Leitura, que aponta a falta de tempo e a falta de interesse como os principais motivos apresentados pelos respondentes "não-leitores" (PANSA, 2012), mesmas razões apresentadas pelos professores de inglês. Por se tratar de educadores, a situação preocupa. Salienta-se aqui que os educadores enfrentam uma longa jornada de trabalho, com muitas turmas,

\footnotetext{
${ }^{9}$ Esperava-se na quarta questão apenas 2 respondentes, mas um dos professores respondeu a essa pergunta também, talvez porque não tenha compreendido que ela era destinada apenas aos indivíduos que assinalaram "não" na primeira questão.
} 
planejamento de aulas, entre outras tarefas que afetam o tempo destinado para leitura literária e diminuem o interesse por essa atividade. Mesmo assim, não se pode negar o direito à literatura aos indivíduos, conforme defende Candido, afinal, todos carecem dessa arte, independentemente das condições que prejudicam a sua inserção na vida dos estudantes.

Com o objetivo de analisar as respostas dos professores que costumam usar os textos literários nas aulas (na quinta pergunta, $68 \%$ dos respondentes afirmaram trabalhar com textos literários nas aulas de inglês), a questão 6 pedia aos educadores que explicassem brevemente as vantagens atribuídas ao processo. Certamente é conhecido por quem atua na área de línguas que motivar o aluno a ler textos, especialmente literários, pode ser um enorme desafio. Entretanto, é importante saber que vários professores demonstram interesse em transpor as dificuldades em favor dos benefícios no desenvolvimento dos estudantes. De todas as respostas obtidas na sexta pergunta, destacase a resposta dada por um dos respondentes:

Os textos literários apresentam um material vasto e rico, a literatura estimula a percepção do aluno como ser humano e como cidadão. Além disso, através do conhecimento dos costumes e valores de outras culturas estrangeiras pode-se estimular nele um interesse e conhecimento ainda maiores da cultura do seu próprio país, permitindo inclusive um trabalho interdisciplinar com os conteúdos de língua portuguesa ou história. (BETH MORGAN)

A partir da resposta do professor, é possível dizer que ele(a) asseverou estar atento(a) ao papel humanizador da literatura, que sensibiliza as pessoas. Além disso, citou que os textos literários podem promover o encontro dos indivíduos com a própria cultura e facilitam a interdisciplinaridade, demonstrando conhecimento de que a literatura não deve ser apresentada como uma disciplina isolada das demais, assim como mencionado por outros dois respondentes. Conforme aponta Showalter (2007), o isolamento é uma das principais razões apresentadas pelos professores americanos e ingleses em relação ao ensino de literatura, apesar de ela ser uma disciplina que sugere com naturalidade a troca com outras matérias, contextos e épocas. No contexto brasileiro, as Diretrizes Curriculares Estaduais destacam que as disciplinas das ciências humanas (Geografia e História) contribuem para a apreensão dos sentidos das obras literárias, oferecendo mais instrumentos aos leitores que podem adquirir uma visão mais ampla do mundo a partir do que leem e do que vivem. 
Se por um lado existem professores que visualizam o papel humanizador da literatura, por outro o avanço no número de leitores literários é ainda afetado pela forma como os textos são abordados. Cinco professores citaram que a utilização da literatura auxilia na transmissão de conteúdos linguísticos. Por exemplo, um dos respondentes disse que o texto possibilita "trabalhar a gramática de maneira mais interessante" (IANTO MORGAN) e outro afirmou que "os alunos poderão perceber que o aprendizado do conteúdo linguístico que muitas vezes eles tem aversão em aprender estão ligados as frases de um texto" (DAVY MORGAN). Assim como o vocabulário pode ser apreendido na leitura, isso pode acontecer com os componentes linguísticos, cujo estudo não deve ser feito de maneira separada, utilizando frases desconexas tiradas do texto. Assim, é indiscutível que o uso da literatura convoca saberes estruturais, mas ela não deve ser pretexto para reforçar o ensino da língua, sem que a complexidade da obra seja colocada em discussão.

Na pergunta 7, de forma geral, todos os respondentes demonstraram interesse em usar a literatura nas aulas de inglês, mas afirmaram que as barreiras que encontram diariamente impedem que isso aconteça. A falta de tempo e a falta de interesse por parte dos alunos apareceram, mais uma vez, como os principais motivos pelos quais os educadores não conseguem inserir os textos nas aulas, seguido pela falta de proficiência linguística dos alunos, pelo retorno frustrante e pela falta do material. Esses fatores encaminham o professor para uma prática mais tradicional. As respostas de alguns educadores sugerem que o livro didático é utilizado porque é mais fácil, "'mas acaba sendo um conteúdo completamente gramatical" (IVOR MORGAN).

A questão 8 perguntava se a escola onde os respondentes trabalham/trabalhavam possui algum plano de incentivo à leitura. De todo o questionário, a pergunta mostrou uma divisão mais equilibrada, uma vez que 12 (48\%) responderam "sim" e 13 (52\%) responderam "não". Isso parece indicar que nem toda escola, conforme os professores, é partícipe na formação de leitores ou toma alguma providência a favor disso. A escola é conhecida por muitos pela responsabilidade em transmitir conteúdos. Utilizando a pesquisa Retratos da Leitura no Brasil como referência, apreende-se que cerca de 1/3 da população prefere a sala de aula para realizar a leitura, algo que vai ao encontro do argumento que a maioria dos indivíduos lê visando interesses acadêmicos (PANSA, 2012).

Os respondentes do questionário também destacaram que as atividades se concentram no lugar onde lecionam, com projetos de leitura em inglês e/ou 
interdisciplinaridade. Dois professores citaram a obrigatoriedade da leitura como parte da avaliação. Outros 2 mencionaram a existência de biblioteca ou salas de leitura. Além disso, os professores citaram que os alunos que leem podem ser premiados, a partir de realização de oficinas e rodas de leitura. Um respondente ainda mencionou que a escola adquire títulos que são veiculados na mídia e aparentemente atraem os estudantes.

A pergunta 10 requeria dos professores se a escola onde eles trabalham/trabalhavam dispõe de recursos adequados para a prática literária em língua inglesa. A maioria dos respondentes declararam “não", o que totalizou 19 respostas $(76 \%)$ contra 6 respostas “sim" (24\%). Essa pergunta conduz ao argumento que, para a comunidade escolar e os próprios docentes, o sucesso ou fracasso quanto à formação de leitores literários depende não somente das atitudes e do comprometimento dos professores com a disciplina, mas também dos incentivos criados pela escola em relação à formação de leitores. Isso sugere que os professores acabam, muitas vezes, trabalhando sozinhos já que a escola parece não se envolver muito na disciplina de língua inglesa. Na maioria dos casos, a escola não cria ou pensa em recursos que possam facilitar o relacionamento dos alunos com a leitura literária em inglês. O resultado apresentado é negativo, porque como os próprios professores mencionaram em outras respostas, a abordagem do texto literário representa um esforço coletivo porque possibilita a interação com diversas disciplinas. A literatura, antes de tudo, visa à formação de um cidadão crítico e sensível aos conflitos que o cercam. Assim, não é responsabilidade exclusiva das disciplinas ligadas ao ensino de línguas formar leitores, mas de toda a comunidade preocupada com a formação do cidadão.

A penúltima questão do questionário perguntava se os respondentes conheciam as teorias de Letramento Crítico. O objetivo dessa pergunta era perceber se os professores demonstram conhecimento sobre um dos principais aspectos a serem considerados na interação do leitor com o texto literário. Nessa pergunta, apesar de a maioria dos respondentes ter alegado compreender do que se trata o Letramento Crítico, percebe-se pelo número de respostas - que menos de $20 \%$ (quatro dos vinte e cinco professores respondentes) conhece bem as teorias que abordam o assunto, enquanto outros demonstram conhecer e ler a respeito, mas de uma forma mais superficial.

Em relação à $12^{\mathrm{a}} \mathrm{e}$ última pergunta, a questão requeria aos respondentes se eles conheciam o conceito de "analbetismo funcional". Assim como o letramento, o assunto em destaque na pergunta 12 tem que ser levado em consideração por todos aqueles que estão preocupados com a formação de leitores, porque é preciso esclarecer que não basta 
saber decodificar as informações de um texto se o leitor não entende criticamente o que está lendo. Na pesquisa, a maioria dos professores demonstrou conhecimento sobre o assunto. Vale ressaltar que essa era uma questão objetiva, em que os professores deveriam selecionar "sim" ou "não", ou seja, eles não conceituram o termo "analfabetismo funcional".

Com base nos apontamentos dos respondentes do questionário, pode-se concluir que os professores demonstram preocupação em formar leitores e muitos estão dispostos a incluir ou já incluiram os textos literários nas aulas. No geral, os educadores citaram muito mais os aspectos positivos em trabalhar com a literatura no ensino de língua inglesa do que as dificuldades. No decorrer do questionário, algumas respostas foram recorrentes, a saber: os textos literários ampliam o conhecimento (11 respostas), possibilitam o trabalho com outros conteúdos, inclusive de outras disciplinas (10 respostas), ampliam os conhecimentos culturais (9 respostas), motivam os estudantes e aumentam o vocabulário (8 respostas cada).

Dessa forma, o problema não está na falta de conhecimento da maioria dos professores, mas na forma equivocada como vários desses profissionais abordam os textos literários. No entanto, não se pode negar que isso está muitas vezes relacionado à falta de tempo e de estrutura de várias instituições. Não é conveniente para a formação de leitores que o texto literário seja apresentado para tirar dele estruturas gramaticais ou para a aquisição descompromissada de vocabulário, conforme sugerem algumas respostas do questionário. Além disso, o nível de leitura literária dos alunos brasileiros não progredirá, enquanto apenas os professores se reservarem o direito de ler e transmitir sua própria leitura aos estudantes. A literatura precisa de comprometimento e do desejo de formar cidadãos críticos, um papel de todos aqueles que alegam interesse em assumir a tarefa de ensinar.

\section{CONSIDERAÇÕES FINAIS}

Ao final desse artigo, constata-se que não parece haver resistência por parte dos professores em afirmar que os textos literários podem promover grandes transformações na vida dos indivíduos, assim como foi apresentado nas teorias que dão suporte à pesquisa. Apesar disso, parece não estar claro ainda qual deve ser o papel da literatura na formação dos indivíduos. Essa constatação originou-se da compilação dos dados do questionário, cujas respostas indicam que há a preocupação dos professores em relação à 
leitura literária, embora nem todos saibam como lidar com a literatura no exercício da profissão.

Além disso, constata-se, a partir da pesquisa, que o cenário educacional brasileiro ainda apresenta muitos paradoxos em relação à formação de leitores, o que resulta no desencontro entre teoria e prática, fator que deu origem a esse estudo. Dessa forma, dois elementos são recorrentes no trabalho com a literatura. Em primeiro lugar, muitos educadores utilizam o texto literário como um pretexto para trabalharem, de maneira supostamente lúdica, as estruturas gramaticais e a aquisição de vocabulário, elementos que fazem parte do contexto da obra literária, mas não constituem os únicos elementos da obra. Dessa forma, não existem justificativas para trabalhar literatura e a língua inglesa desarticuladamente, conforme explorado no decorrer desta pesquisa. Em segundo, alguns educadores acreditam que a função primordial da literatura é proporcionar entretenimento gratuito. Entretanto, o texto literário é um instrumento poderoso que pode auxiliar a formação de cidadãos capazes de julgar criticamente a validade das informações que recebem no cotidiano, ao oferecer o inédito que, de alguma forma, é útil para despertar a sensibilidade nos leitores.

Em relação ao papel da escola, é nessa instituição que os brasileiros, assim como em diversos países latino-americanos, depositam toda a responsabilidade pela sua formação. De fato, a escola é o palco apropriado para o exercício literário e qualquer solução para intervir na defasagem de leitura deve passar por uma tomada de consciência da instituição de ensino. Contudo, a partir da pesquisa, pode-se dizer que o professor, geralmente, é forçado a assumir sozinho o papel de formador de leitores ou de transmissor de conteúdos. Isso significa que as escolhas dependem muito mais do professor, que muitas vezes, apesar de leitor, desconhece como trabalhar textos literários na sua disciplina, conforme pode ser visto na análise do questionário. Uma síntese disso é a resposta dada por um dos professores que não trabalha com texto literário, mas gostaria de poder fazê-lo. Em seu depoimento, o professor justifica que

não uso porque o nível de proficiência dos meus alunos é sempre iniciante, como passo muito tempo tentando construir uma base da língua com eles, tenho dificuldade de incluir textos literários que sempre exigem um conhecimento maior. Em geral, eles acham muito difícil ler em inglês. (OWEN MORGAN)

Tomando como base o fragmento do respondente acima, não se pode afirmar a inexistência de um caminho teórico para o trabalho com literatura. O problema não está 
na falta ou inadequação das teorias que se dedicam ao estudo do processo de ensinoaprendizagem da literatura, tampouco nas metodologias, mas nas barreiras que as afastam da prática docente. As condições infraestruturais medíocres encontradas em muitas escolas, por exemplo, afetam a qualidade das aulas. Ademais, não são poucos os professores que, devido às longas horas de trabalho em sala de aula e um número excessivo de turmas, não têm tempo de ler e atualizar os conhecimentos adquiridos durante a formação docente. Os documentos oficiais do Estado também reconhecem o papel da literatura na formação do cidadão, embora a falta de condições para que isso seja efetivado impeça a articulação entre a teoria e a prática, sugerindo a realização de outros estudos que possam promover esse encontro de maneira eficiente e contínua.

\section{AGRADECIMENTO}

Agradeço à professora Dra. Jaqueline Bohn Donada pelas críticas feitas a esse trabalho.

\section{REFERÊNCIAS BIBLIOGRÁFICAS}

AGUIAR, V. T. de. O Saldo da Leitura. In: DALVI, M. A.; REZENDE, N. L. de; JOVERFALEIROS, R.(orgs). Leitura de literatura na escola. São Paulo: Parábola, 2013.

BORDINI, M. da G; AGUIAR, V. T. Método Recepcional. In: Literatura: a formação do leitor: alternativas metodológicas. Porto Alegre: Mercado Aberto, 1993. CANDIDO, A.A literatura e a formação do homem. In: Ciência e cultura. São Paulo, v. 24, n.9, pp. 803-809, set. 1972. . O direito à literatura. In: Vários escritos. $3^{\mathrm{a}}$ ed. rev. ampl. São Paulo: Duas Cidades, 1995, pp. 235-263. CRUZ, J. H. R. The Role of Literature and Culture in English Language Teaching. Relinguística aplicada: Cidade do México, 2010. Disponível em: $<$ http://relinguistica.azc.uam.mx/no007/no07_art09.pdf $>$ Acesso em 03/04/2014. GIMENEZ, T. N.; PERIN, J. O. R.; SOUZA, M. M. Ensino de Inglês em Escolas Públicas: o que pensam pais, alunos e profissionais da educação. SIGNUM: Londrina, 2003, p. 167-182.

LAJOLO, M. Usos e abusos da literatura na escola. Rio de Janeiro: Globo, 1982. MARCONI, M. de A.; LAKATOS, E. Técnicas de Pesquisa. 5.ed., São Paulo: Atlas, 2002.

MARTINS, I. A literatura no EM: quais os desafios do professor? In: BUNZEN, C.; MENDONÇA, M. (orgs.). Português no Ensino Médio e formação do professor. São Paulo: Parábola Editorial, 2006.

National Council of Teachers of English. Standards for the English language arts. Disponível em: <http://www.ncte.org/standards/ncte-ira> Acesso em: 20 Jan 2015. PANSA, K. Fazer do Brasil um país de leitores é o nosso desafio. In: FAILLA, Z. (org.). Retratos da leitura no Brasil 3. Instituto Pró-livro. São Paulo: Imprensa Oficial, 2012. Disponível em: http://www.imprensaoficial.com.br/retratosdaleitura/RetratosDa LeituraNoBrasil3-2012.pdf> Acesso em: 08/10/2014. 
PARANÁ. Diretrizes Curriculares da Educação Básica: Língua Estrangeira Moderna. Paraná: SEED, 2008.

ROUXEL, A. Aspectos metodológicos do ensino da literatura. In: DALVI, Maria A.; REZENDE, N. L. de; JOVER-FALEIROS, R. Leitura de literatura na escola. São Paulo: Parábola, 2013.

SHOWALTER, E. Teaching Literature. Oxford: Blackwell Publishing, 2007.

ZILBERMAN, R. O papel da literatura na escola. Via Atlântica (USP), v. 14, pp. 11 22, 2009. 